\title{
New Zealand Health Quality \& Safety Commission infection prevention and control programmes: evidence for sustained improvement in infection prevention interventions
}

\author{
S Roberts ${ }^{*}, \mathrm{D}$ Jowitt \\ From 3rd International Conference on Prevention and Infection Control (ICPIC 2015) \\ Geneva, Switzerland. 16-19 June 2015
}

\section{Introduction}

In 2010 the New Zealand Health Quality \& Safety Commission was established. Since 2011 the Commission has sponsored three infection prevention and control programmes; improving hand hygiene compliance, reducing central line associated bacteraemia and surgical site infections.

\section{Objectives}

The aim is to report on the progress to date of these quality improvement programmes.

\section{Methods}

Hand Hygiene New Zealand adopted the WHO '5 moments for hand hygiene' approach using Front-line ownership (FLO) improvement methodology, Target CLAB ZERO used the Institute for Healthcare Improvement collaborative methodology and the National Surgical Site Infection Improvement (SSII) Programme has used an inclusive approach utilising the 'right tool for the right job'. Each programme has a set of process measure and outcome markers against which performance is measured. These, called the Quality and Safety Markers (QSM), are reported to the Minister of Health. Performance over time is used to support quality improvement.

\section{Results}

There has been has been a sustained improvement in hand hygiene compliance. The current target is $75 \%$ with the target moving to $80 \%$ by June 2015 . Improvement in the

Health Quality \& Safety Commission, Infection Prevention and Control Programme, Auckland, New Zealand 